\title{
Very Short-Term Effects of the Dipeptidyl Peptidase-4 Inhibitor Sitagliptin on the Secretion of Insulin, Glucagon, and Incretin Hormones in Japanese Patients with Type 2 Diabetes Mellitus: Analysis of Meal Tolerance Test Data
}

\author{
Kazuki Murai · Tomoyuki Katsuno · Jun-ichiro Miyagawa \\ Toshihiro Matsuo $\cdot$ Fumihiro Ochi $\cdot$ Masaru Tokuda $\cdot$ \\ Yoshiki Kusunoki $\cdot$ Masayuki Miuchi $\cdot$ Mitsuyoshi Namba
}

Published online: 25 November 2014

(C) The Author(s) 2014. This article is published with open access at Springerlink.com

\begin{abstract}
Background Sitagliptin inhibits dipeptidyl peptidase-4, which inactivates the incretin hormones glucagon-like peptide-1 (GLP-1) and glucose-dependent insulinotropic polypeptide. To assess its antidiabetic potency, we used meal tolerance tests (MTTs) to determine the very shortterm effects of sitagliptin on plasma concentrations of insulin and glucagon.

Methods On day 1, patients with newly diagnosed or uncontrolled type 2 diabetes mellitus started a calorierestricted diet. On day 2, the first MTT was performed, before treatment with sitagliptin $50 \mathrm{mg} /$ day started later the same day. On day 5, a second MTT was performed. Area under the concentration-time curves (AUCs) of relevant laboratory values were calculated [AUC from time zero to $2 \mathrm{~h}\left(\mathrm{AUC}_{0-2 \mathrm{~h}}\right)$ and from time zero to $\left.4 \mathrm{~h}\left(\mathrm{AUC}_{0-4 \mathrm{~h}}\right)\right]$.

Results Fifteen patients were enrolled. AUCs for postprandial plasma glucose were decreased after 3 days of sitagliptin treatment $\left[\mathrm{AUC}_{0-2 \mathrm{~h}} 457 \pm 115 \mathrm{mg} / \mathrm{dL} \cdot \mathrm{h}(25.4\right.$ $\pm 6.4 \mathrm{mmol} / \mathrm{L} \cdot \mathrm{h}) \quad$ to $369 \pm 108 \mathrm{mg} / \mathrm{dL} \cdot \mathrm{h} \quad(20.5 \pm 6.0$ $\mathrm{mmol} / \mathrm{L} \cdot \mathrm{h}) ; \quad \mathrm{AUC}_{0-4 \mathrm{~h}} 896 \pm 248 \mathrm{mg} / \mathrm{dL} \cdot \mathrm{h} \quad(49.7 \pm 13.8$ $\mathrm{mmol} / \mathrm{L} \cdot \mathrm{h})$ to $701 \pm 246 \mathrm{mg} / \mathrm{dL} \cdot \mathrm{h}(38.9 \pm 13.7 \mathrm{mmol} / \mathrm{L} \cdot \mathrm{h})$; both $p<0.001]$. $\mathrm{AUC}_{0-2 \mathrm{~h}}$ and $\mathrm{AUC}_{0-4 \mathrm{~h}}$ for postprandial plasma glucagon also decreased: $195 \pm 57$ to $180 \pm 57 \mathrm{pg}$ / $\mathrm{mL} \cdot \mathrm{h}(p<0.05)$ and $376 \pm 105$ to $349 \pm 105 \mathrm{pg} / \mathrm{mL} \cdot \mathrm{h}$
\end{abstract}

K. Murai · T. Katsuno $(\bowtie) \cdot$ J. Miyagawa · T. Matsuo ·

F. Ochi - M. Tokuda - Y. Kusunoki - M. Miuchi · M. Namba

Division of Diabetes, Endocrinology and Metabolism,

Department of Internal Medicine, Hyogo College of Medicine,

1-1, Mukogawa-cho, Nishinomiya, Hyogo 663-8501, Japan

e-mail: katsunoa@hyo-med.ac.jp

T. Katsuno $\cdot$ M. Namba

Division of Innovative Diabetes Treatment, Hyogo College of

Medicine, Nishinomiya, Hyogo, Japan $(p<0.01)$, respectively. The $\mathrm{AUC}_{0-2 \mathrm{~h}}$ [median with quartile values $(25 \%, 75 \%)]$ for active GLP-1 increased: 10.5 (8.5, $15.2)$ to $26.4(16.7,32.4) \mathrm{pmol} / \mathrm{L} \cdot \mathrm{h}(p=0.03)$.

Conclusions Very short-term (3-day) treatment with sitagliptin decreases postprandial plasma glucose significantly. This early reduction in glucose may result partly from suppression of excessive glucagon secretion, through a direct effect on active GLP-1. Improvement in postprandial plasma glucose, through suppression of glucagon secretion, is believed to be an advantage of sitagliptin for the treatment of patients with type 2 diabetes.

\section{Key Points}

The mechanism of the short-term effects of sitagliptin is unclear.

In the very short-term (after 3 days) sitagliptin treatment, the postprandial glucose concentration in Japanese patients with newly diagnosed or uncontrolled type 2 diabetes mellitus was significantly lower than the concentration on the day before sitagliptin treatment started (i.e., on the first day of the calorie-restricted diet).

This result may be partly attributable to sitagliptin rapidly suppressing excessive glucagon secretion.

\section{Introduction}

According to the 2007 National Health and Nutrition Survey, undertaken by the Japanese Ministry of Health, 
Labour and Welfare, the total number of Japanese persons with prediabetes or diabetes mellitus, and for whom diabetes is strongly suspected or cannot be ruled out, is estimated to be 22.1 million [1]. Compared with 10 years ago, the number of people suspected to have diabetes has increased by about 1.3 times, and it continues to rise. Indeed, the number of persons with type 2 diabetes is increasing in every country [2]. In 2011, 366 million people worldwide were reported to have diabetes, and this figure is predicted to increase to 552 million by 2030 [2].

Unfortunately, efforts to reduce the number of patients with type 2 diabetes have been unsuccessful, despite the availability of a range of oral antidiabetic agents and various types of insulin derivatives. Dipeptidyl peptidase-4 (DPP-4) inhibitors, which work through mechanisms that differ from those of antidiabetics and insulins, and can be used either alone or in combination with them, have been introduced to the global market. Sitagliptin is a DPP-4 which has a favorable efficacy and safety profile that has been validated in many countries [3], and evidence supporting its use is accumulating in Japan [4-8]. However, the mechanism of the short-term effects of sitagliptin that lower glucose concentrations has yet to be completely elucidated.

One of the clinical benefits of sitagliptin is that it is associated with minimal adverse effects compared with other oral hypoglycemic agents. Therefore, it can be used safely by elderly persons, who are at increased risk of hypoglycemia. Moreover, weight gain and other gastrointestinal adverse effects are uncommon in patients receiving sitagliptin [9].

Incretins are gut-derived hormones that are secreted from $\mathrm{K}$ and $\mathrm{L}$ cells in response to nutrients, especially carbohydrates and fat. The two major incretins, glucagon-like peptide-1 (GLP-1) and glucose-dependent insulinotropic polypeptide (GIP), enhance glucosedependent insulin secretion from $\beta$ cells. Moreover, GLP-1 may play an important role in the biosynthesis and secretion of insulin itself, and it suppresses excessive glucagon secretion from $\alpha$ cells in the pancreas. Both incretins are rapidly degraded by the protein-digesting enzyme DPP-4. Sitagliptin exerts its antidiabetic actions through the incretin pathway by inhibiting the activity of DPP-4 [10].

Despite previous studies that evaluated the effects of sitagliptin on glucagon secretion and blood glucose concentration, to our knowledge, the effects of sitagliptin in the very short-term have not been fully investigated. Therefore, we performed an observational study to determine the very short-term effects of sitagliptin on plasma concentrations of insulin, incretins, and glucagon.

\section{Patients and Methods}

\subsection{Patients}

Patients admitted to our department (Department of Internal Medicine, Hyogo College of Medicine, Nishinomiya, Japan) were eligible to participate in the study if they had newly diagnosed or uncontrolled type 2 diabetes with a glycosylated hemoglobin $\left(\mathrm{HbA}_{1 \mathrm{c}}\right)$ value $\geq 6.1 \%$ (National Glycohemoglobin Standardization Program). The enrollment period was between April 2010 and September 2012. The following patients were excluded from the study: those with a history of severe ketosis, diabetic coma or pre-coma, or type 1 diabetes; those scheduled for or who had undergone surgery; those with a severe infection or serious injury; pregnant, possibly pregnant, and lactating women; those with moderate or severe kidney dysfunction (creatinine clearance $<30 \mathrm{~mL} / \mathrm{min}$; and serum creatinine $\geq 1.5 \mathrm{mg} / \mathrm{dL}$ in men and $\geq 1.3 \mathrm{mg} / \mathrm{dL}$ in women); and those receiving insulin treatment.

The study was performed in accordance with the Declaration of Helsinki. Patients were fully informed about the study and gave written informed consent voluntarily. The study protocol was approved by the ethics committee of Hyogo College of Medicine. The study was registered retrospectively on the UMIN Clinical Trials Registry (http://www.umin.ac.jp/ctr/index.htm) under the unique trial number UMIN000012642.

\subsection{Treatment}

For patients receiving diet and exercise therapy before admission, sitagliptin $50 \mathrm{mg} /$ day was used alone. Patients using antidiabetic agents other than DPP-4 inhibitors before admission were instructed to continue the treatment. For those receiving oral medication in addition to diet and exercise therapy, sitagliptin $50 \mathrm{mg} /$ day was added as part of combination drug therapy. If symptomatic hypoglycemia was found after the addition of sitagliptin, the concomitant antidiabetic agent was reduced or discontinued.

\subsection{Meal Tolerance Tests}

JANEF E460F18 ${ }^{\circledR}$ (Kewpie Corporation, Tokyo, Japan), containing a total of $460 \mathrm{kcal}$ (carbohydrate $56.5 \mathrm{~g}$, protein $18 \mathrm{~g}$, and lipid $18 \mathrm{~g}$ ), was used for the meal tolerance tests (MTTs). On day 1 of admission, patients started an energyrestricted diet (25 kcal/kg daily). On day 2, the first MTT was performed to measure baseline values; treatment with sitagliptin $50 \mathrm{mg}$ /day also began on day 2 . Three days later, on day 5 , the second MTT was performed to allow evaluation of changes in relevant laboratory values. In each MTT, blood samples were collected $10 \mathrm{~min}$ before and 0 , $15,30,60,120$, and $240 \mathrm{~min}$ after the meal. 
The following laboratory values were measured: plasma glucose (PG), $\mathrm{HbA}_{1 \mathrm{c}}$, glycoalbumin (GA), urinary C-peptide immunoreactivity, immunoreactive insulin (IRI), intact proinsulin, glucagon, active GLP-1, and total GIP. Glucose, $\mathrm{HbA}_{1 \mathrm{c}}$, and GA were measured by enzyme methods; IRI by chemiluminescent immunoassay; intact proinsulin by ELISA; and glucagon by double-antibody radioimmunoassay. Sample tubes containing aprotinin and EDTA-2Na were used for measurement of active GLP-1 and total GIP. A blood sample containing DPP-4 inhibitor $10 \mu \mathrm{g}$ per $1 \mathrm{~mL}$ of blood was inserted into the sample tube. The samples were centrifuged immediately to separate the plasma, and then stored at $-80^{\circ} \mathrm{C}$. Glucagon-Like Peptide-1 (Active) ELISA kit (Millipore, St. Charles, MO, USA) was used to measure active GLP-1. Human GIP (Total) ELISA kit (Millipore) was used to measure total GIP.

The coefficients of variation of active GLP- 1 were $8.0 \%$ in intra-assay and $7.4 \%$ in inter-assay evaluations. Those of human GIP (total) were $6.5 \%$ in intra-assay and $3.48 \%$ in inter-assay evaluations. The detection limit of the GLP-1 and GIP kits were $2.0 \mathrm{pmol} / \mathrm{L}$ and $4.2 \mathrm{pg} / \mathrm{mL}$, respectively. Two indices, the homeostasis model assessment (HOMA) for insulin resistance (HOMA-IR) and for $\beta$ cell function (HOMA- $\beta$ ), were calculated using the following formulae:

HOMA-IR $=\mathrm{IRI} \times \mathrm{PG} / 405$

HOMA $-\beta=\mathrm{IRI} /(\mathrm{PG}-63) \times 360$

\subsection{Statistical Analysis}

Measurements were plotted, and area under the concentration-time curves (AUCs) from time zero to $2 \mathrm{~h}\left(\mathrm{AUC}_{0-2 \mathrm{~h}}\right)$ and to $4 \mathrm{~h}\left(\mathrm{AUC}_{0-4 \mathrm{~h}}\right)$ were calculated by using the trapezoidal rule. Data are expressed as numbers or means \pm standard deviation or as medians with quartile values $(25 \%, 75 \%)$. The two-way repeated measured ANOVA with ad hoc multiple comparison method (Fisher's least significant difference procedure) was used to compare baseline ( $0 \mathrm{~min})$ and postprandial laboratory values, as well as values before (i.e., on the first day of the calorie-restricted diet) and after sitagliptin treatment. Changes in AUCs before and 3 days after sitagliptin treatment were analyzed by paired $t$ test or Wilcoxon signed rank test according to whether or not the data had normal distribution. A $p$ value $<0.05$ was considered statistically significant.

\section{Results}

\subsection{Patient characteristics}

Table 1 summarizes the baseline characteristics of the 15 patients enrolled. Most patients were receiving oral
Table 1 Patient characteristics at baseline $(n=15)$

\begin{tabular}{ll}
\hline Characteristic & $n$ or mean $\pm \mathrm{SD}$ \\
\hline Male/female & $8 / 7$ \\
Age (years) & $64.7 \pm 10.5$ \\
Body mass index $\left(\mathrm{kg} / \mathrm{m}^{2}\right)$ & $23.7 \pm 3.8$ \\
Duration of diabetes mellitus (years) & $10.1 \pm 7.1$ \\
Glycosylated hemoglobin value $(\%)$ & $8.56 \pm 1.80$ \\
Fasting plasma glucose $[\mathrm{mg} / \mathrm{dL}(\mathrm{mmol} / \mathrm{L})]$ & $154 \pm 39$ \\
& $(8.5 \pm 2.2)$ \\
Immunoreactive insulin $(\mu \mathrm{U} / \mathrm{mL})$ & $4.95 \pm 2.18$ \\
Glycoalbumin $(\%)$ & $20.3 \pm 3.0$ \\
Intact proinsulin (pmol/L) & $19.3 \pm 5.8$ \\
Urinary C-peptide immunoreactivity ( $\mu \mathrm{g} /$ & $82.5 \pm 36.4$ \\
day) & \\
HOMA- $\beta$ & $24.3 \pm 16.6$ \\
HOMA-IR & $1.86 \pm 1.04$ \\
Previous antidiabetic medications & \\
Sulfonylureas & 11 \\
Biguanides (metformin) & 6 \\
Thiazolidinedione & 3 \\
$\alpha$-Glucosidase inhibitor & 1 \\
Glinide & 1 \\
None & 1 \\
\hline
\end{tabular}

HOMA- $\beta$ homeostasis model assessment for $\beta$ cell function, HOMA$I R$ homeostasis model assessment for insulin resistance, $S D$ standard deviation

antidiabetic therapy before study entry, but their glycemic metabolism had not been well-controlled [mean fasting blood glucose and $\mathrm{HbA}_{1 \mathrm{c}}$ were $154 \mathrm{mg} / \mathrm{dL}(8.5 \mathrm{mmol} / \mathrm{L})$ and $8.6 \%$, respectively]. Throughout the study period, none of the patients required changes to any concomitant antidiabetic agents.

\subsection{Postprandial Changes in Laboratory Values}

Table 2 shows concentrations of PG, IRI, glucagon, active GLP-1, and total GIP before (i.e., on the first day of the calorie-restricted diet) and after sitagliptin treatment, as well as their AUCs.

Figure 1 summarizes the results for glucose. With sitagliptin treatment, glucose was significantly lower at all timepoints, except $15 \mathrm{~min}$, throughout the MTT, including 0 min, compared with equivalent values for the day before sitagliptin treatment started (i.e., on the first day of the calorie-restricted diet). With sitagliptin, $\mathrm{AUC}_{0-2 \mathrm{~h}}$ and $\mathrm{AUC}_{0-4 \mathrm{~h}}$ for glucose were also decreased (both $p<0.001$ ).

Figure 2 summarizes the results for glucagon. Before sitagliptin treatment (i.e., on the calorie-restricted diet alone), glucagon at all timepoints throughout the MTT was increased significantly from baseline $(0 \mathrm{~min})$. However, after sitagliptin treatment, glucagon was not 


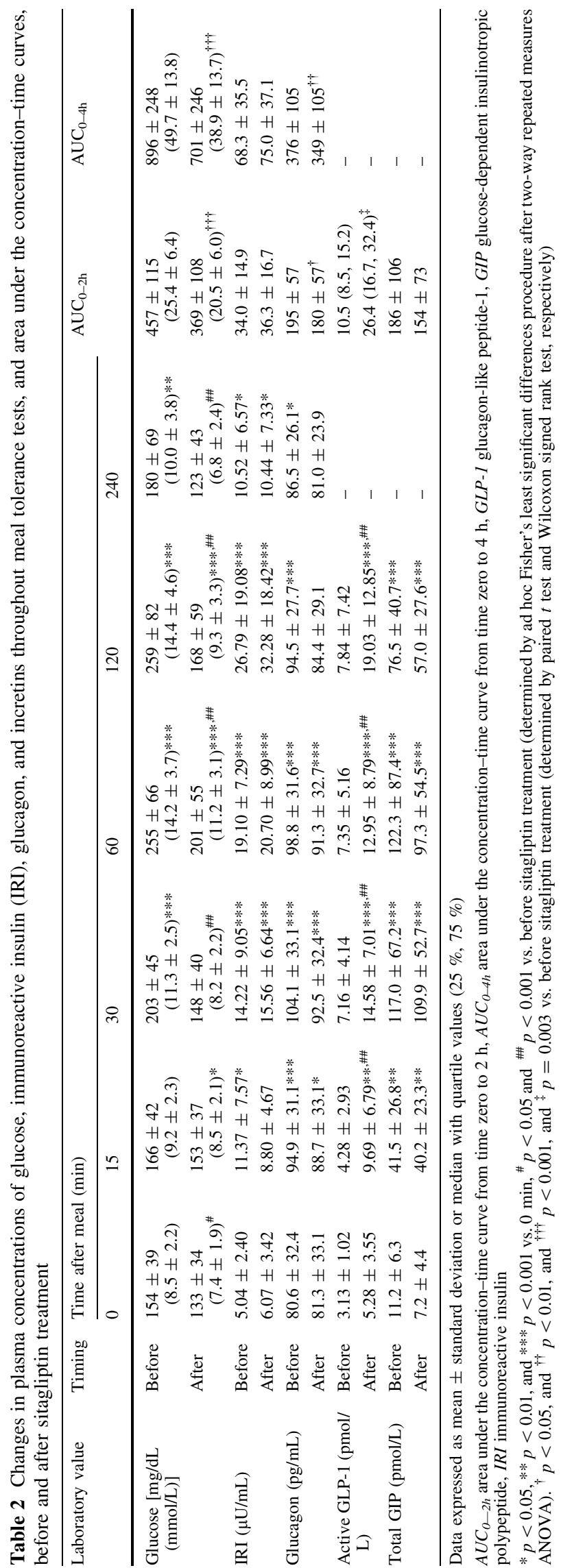

significantly increased at 120 and $240 \mathrm{~min}$. With sitagliptin, $\mathrm{AUC}_{0-2 \mathrm{~h}}$ and $\mathrm{AUC}_{0-4 \mathrm{~h}}$ for glucagon were decreased ( $p=0.016$ and $p=0.006$, respectively).

Figure 3 summarizes the results for active GLP-1. With sitaglipin, active GLP-1 was significantly higher at all timepoints after 0 min throughout the MTT compared with baseline ( $0 \mathrm{~min})$ and compared with equivalent values for the day before sitagliptin treatment started. In contrast, before treatment (i.e., on the calorie-restricted diet alone), active GLP showed no significant change from baseline $(0 \mathrm{~min})$ at any timepoint. Sitagliptin increased $\mathrm{AUC}_{0-2 \mathrm{~h}}$ for active GLP-1 $(p<0.001)$.

Figure 4 summarizes the results for total GIP. Both before and after sitagliptin treatment, total GIP at all timepoints throughout the MTT was increased significantly from baseline $(0 \mathrm{~min})$.

\subsection{Adverse Reactions}

Major adverse reactions were mild gastric symptoms, such as nausea and upper abdominal discomfort. No severe adverse reactions were observed.

\section{Discussion}

In the present study, we investigated the very short-term effects of sitagliptin $50 \mathrm{mg}$ on insulin and glucagon by using MTTs to measure relevant laboratory values in 15 Japanese patients with type 2 diabetes, and to clarify the mechanism by which sitagliptin lowers blood glucose. In the very short-term (after 3 days of sitagliptin treatment), the postprandial glucose concentration was significantly lower than the concentration on the day before sitagliptin treatment started, when the patients had started a calorierestricted diet. With sitagliptin, postprandial PG was significantly decreased at all but one timepoint throughout the MTT, the $\mathrm{AUC}_{0-2 \mathrm{~h}}$ and $\mathrm{AUC}_{0-4 \mathrm{~h}}$ were not significantly increased for IRI but were significantly decreased for glucagon, active GLP-1 was significantly increased at all timepoints after 0 min throughout the MTT, and the $\mathrm{AUC}_{0-2 \mathrm{~h}}$ for active GLP-1 was significantly increased. These results are discussed and interpreted in turn below. After 3 days of sitagliptin treatment, postprandial PG was significantly decreased at all but one timepoint throughout the MTT, compared with equivalent values for the calorierestricted diet alone. This finding is consistent with those of previous studies, in that the rapid effects of sitagliptin plateau after 2 days [11]. The effects of sitagliptin on glucose are caused by its enhancement of insulin secretion and suppression of glucagon secretion [12]. The effects of sitagliptin on blood glucose have been attributed to glucose-dependent endogenous insulin secretion and 
Fig. 1 Meal tolerance test results for glucose: changes in

(a) plasma concentration and

(b) area under the

concentration-time curve

(AUC). $* p<0.05, * * p<0.01$, and $* * * p<0.001$ versus $0 \mathrm{~min}$, and ${ }^{\#} p<0.05$ and ${ }^{\# \#} p<0.001$ versus before sitagliptin treatment (i.e., calorie-restricted diet only) (determined by Fisher's least significant difference procedure after twoway repeated ANOVA). Differences in AUCs were analyzed by paired $t$ test. Graphs were plotted using means \pm standard deviation

Fig. 2 Meal tolerance test results for glucagon: changes in (a) plasma concentration and

(b) area under the concentration-time curve (AUC). $* p<0.05$ and $* * * p<0.001$ versus 0 min (determined by Fisher's least significant difference procedure after two-way repeated ANOVA). Differences in AUCs were analyzed by paired $t$ test. Graphs were plotted using means \pm standard deviation
A

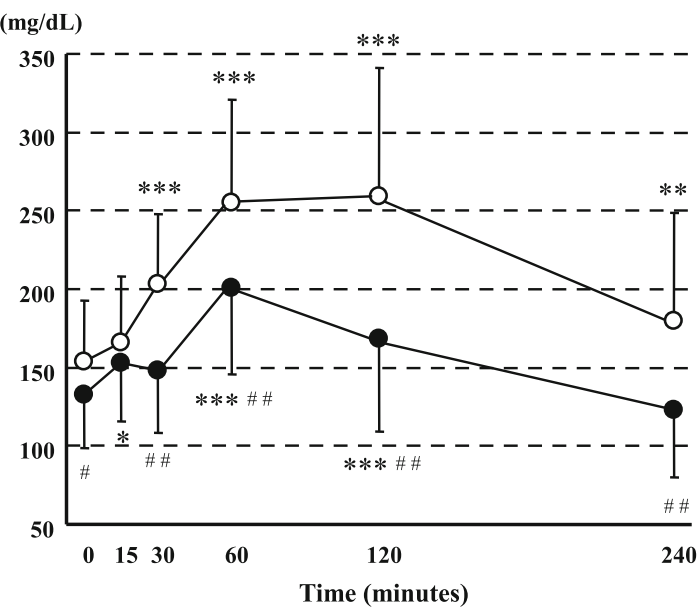

A

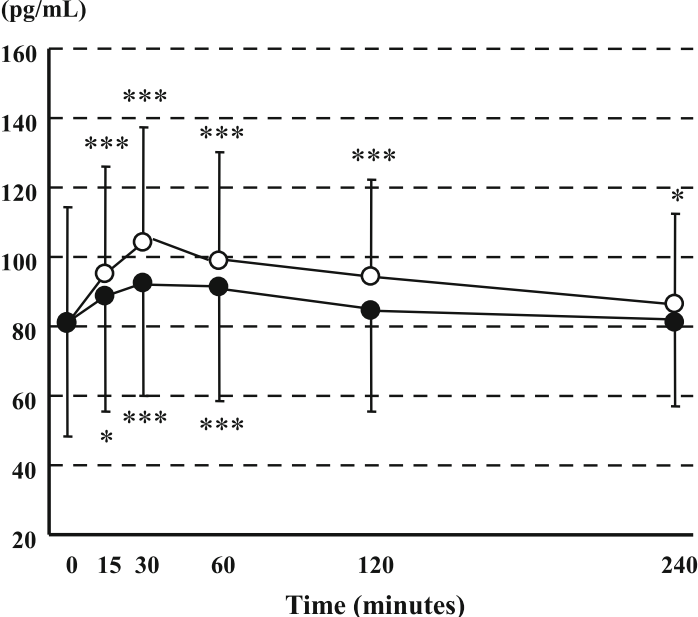

$\bigcirc \square$ : before sitagliptin
B

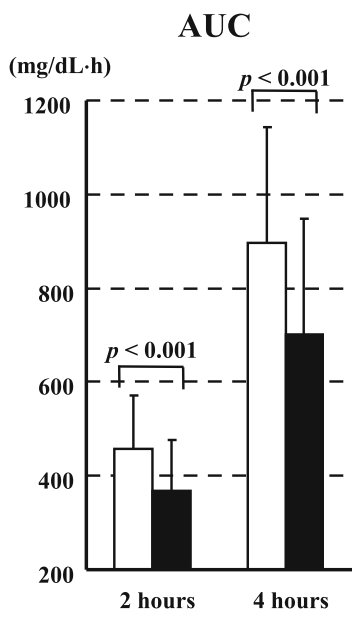

B

- : after sitagliptin

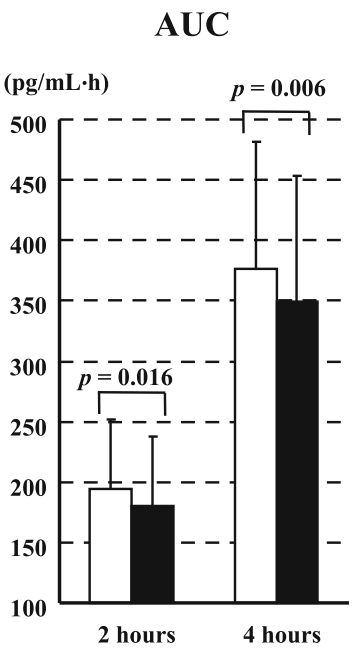

glucagon suppression in the middle- or long-term. In our study, we investigated these effects in the very short-term, so our findings are novel in this respect. Patients received the same calorie-restricted diet $(25 \mathrm{kcal} / \mathrm{kg}$ daily $)$ and underwent MTT to determine the effects of sitagliptin. Therefore the calorie-restricted diet may have contributed to the observed changes in postprandial PG by causing glucose toxicity, so the improvement may not be attributable to sitagliptin alone.

We found that the $\mathrm{AUC}_{0-2 \mathrm{~h}}$ and $\mathrm{AUC}_{0-4 \mathrm{~h}}$ for IRI did not increase significantly. In contrast, with sitagliptin, the $\mathrm{AUC}_{0-2 \mathrm{~h}}$ and $\mathrm{AUC}_{0-4 \mathrm{~h}}$ for glucagon were significantly decreased. Therefore, the improvement in postprandial blood glucose shown in the present study may be more strongly associated with suppression of glucagon secretion than with enhancement of insulin secretion with sitagliptin treatment in the very short-term. This finding contrasts with the results of previous studies, which have shown that DPP-4 inhibitors, including sitagliptin, may improve acute insulin response in Japanese patients with type 2 diabetes by increasing early-phase insulin secretion $[6,13]$. The previous studies had a longer follow-up period (about 12 weeks), and therefore secondary effects, including glucose toxicity, could have contributed to the response. In contrast, our study was very short-term, so our results reflect the direct effects of sitagliptin.

An increase in intraislet insulin would suppress glucagon secretion from $\alpha$ cells in a paracrine manner. The intraislet interaction of $\alpha$ and $\beta$ cells may suppress glucagon secretion in the absence of changes to insulin concentration in the peripheral circulation [14]. Glucagon secretion may be suppressed either by a secondary effect, 
Fig. 3 Meal tolerance test results for active glucagon-like peptide-1: changes in (a) plasma concentration and (b) area under the concentration-time curve (AUC). $* * p<0.01$ and ***p $p 0.001$ versus $0 \mathrm{~min}$, and ${ }^{\# \#} p<0.001$ versus before sitagliptin (determined by Fisher's least significant difference procedure method after two-way repeated ANOVA). Differences in AUCs were analyzed by Wilcoxon signed rank test. Panel a was plotted using means \pm standard deviation, and panel $\mathbf{b}$ using medians and quartile values (minimum $25 \%$, and maximum $75 \%)$

Fig. 4 Meal tolerance test results for total glucosedependent insulinotropic peptide: changes in (a) plasma concentration and (b) area under the concentration-time curve (AUC). $* * p<0.01$ and $* * * p<0.001$ versus 0 min (determined by Fisher's least significant difference procedure after two-way repeated ANOVA). Graphs were plotted using means \pm standard deviation

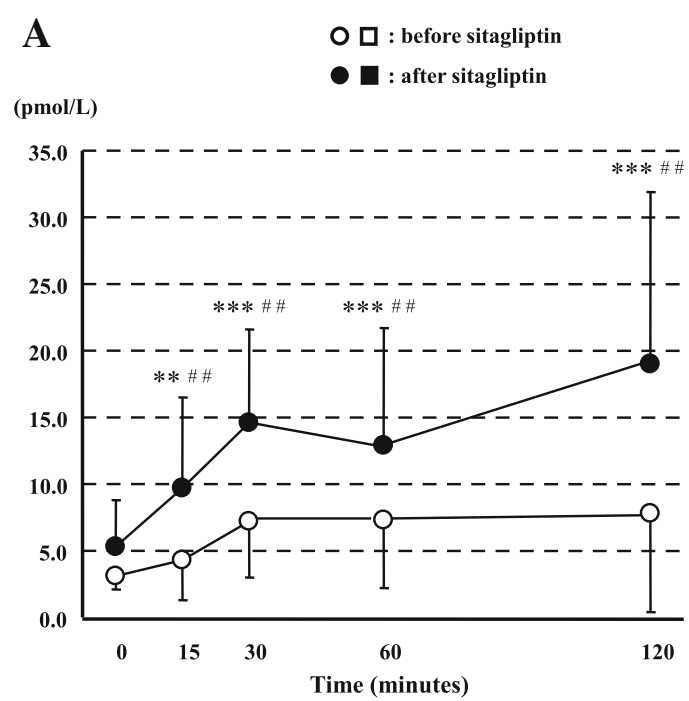

B

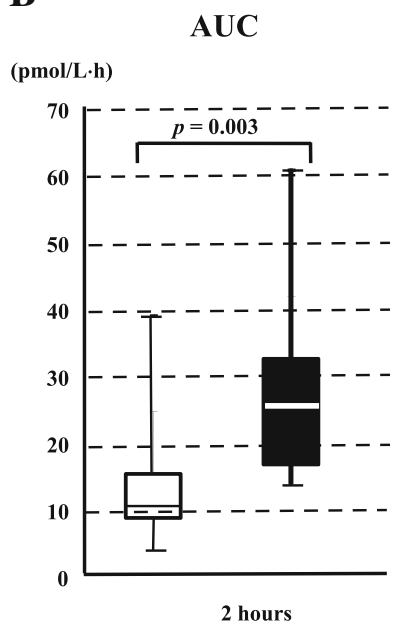

A

$(\mathrm{pmol} / \mathrm{L})$

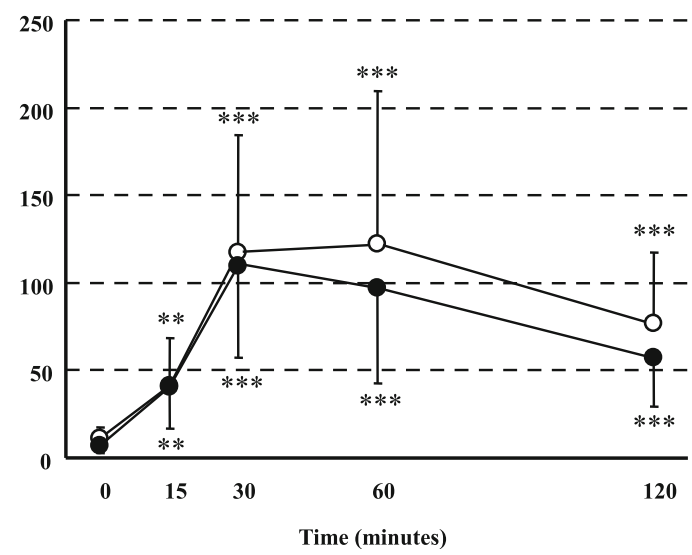

$\bigcirc \square$ : before sitagliptin

- $\square$ : after sitagliptin
B

(pmol/L·h)

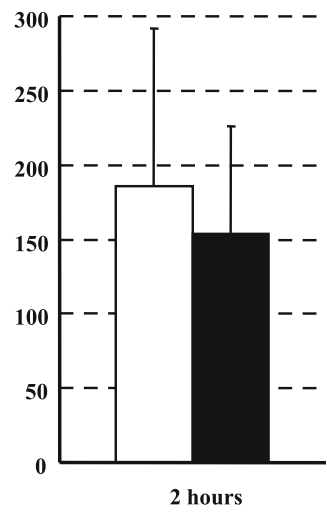

in response to increased intraislet insulin concentration, or by direct inhibition, through the potentiation of active GLP-1 in plasma.

In the present study, with sitagliptin, active GLP-1 was significantly increased at all timepoints after $0 \mathrm{~min}$ throughout the MTT compared with equivalent values for the calorie-restricted diet alone, and the $\mathrm{AUC}_{0-2 \mathrm{~h}}$ for active GLP-1 increased significantly. In contrast, the $\mathrm{AUC}_{0-2 \mathrm{~h}}$ for IRI was barely increased. We believe that the observed suppression of glucagon secretion may result at least partly from a direct effect on active GLP-1 rather than a response to increased insulin secretion from $\beta$ cells. It has been suggested that suppression of glucagon secretion by GLP-1 involves a direct action on pancreatic $\alpha$ cells as well as an indirect action through somatostatin-secreting $\delta$ cells [15]. However, this proposed mechanism remains controversial, with contradictory reports arguing against the expression of GLP-1 receptors on $\alpha$ cells [16].

GIP is secreted from $\mathrm{K}$ cells in the upper portion of the small intestine in response to stimulation by ingestion of glucose and fats. GIP, like GLP-1, could be inactivated by DPP-4. Sitagliptin increases plasma concentrations of active GIP by inhibiting DPP-4. Conversely, sitagliptin decreases plasma concentrations of total GLP-1 and total GIP [17]. In the present study, the $\mathrm{AUC}_{0-2 \mathrm{~h}}$ for total GIP decreased only slightly with sitagliptin treatment. This effect is caused partly by negative feedback from its active form [18]. We previously reported that plasma GLP-1 is more associated with inhibition of glucagon secretion, and that plasma GIP is more associated with promotion of insulin secretion, in healthy subjects [19]. However, in patients with type 2 diabetes, the effect of GIP on insulin 
secretion may be reduced; consequently, the promotion of insulin secretion is primarily mediated by GLP-1.

Impaired insulin secretion is a major pathophysiological feature of type 2 diabetes. Decreased or delayed insulin secretion is responsible for increases in postprandial PG, especially in the early stages of the disease. Excessive and/ or paradoxical secretion of glucagon, even in the hyperglycemic condition, also contributes to increased postprandial hyperglycemia. We found in a previous morphological study that as well as a decrease in the number of $\beta$ cells, there is an increase in the number of $\alpha$ cells in pancreatic islets in patients with long-standing type 2 diabetes [20].

Our findings suggest that an increase in GLP-1 and suppression of glucagon secretion may underlie any early improvement in PG caused by sitagliptin. However, a larger-scale comparative study is necessary to confirm this mechanism of action and to identify any patient groups in whom these effects are more easily recognized. The finding that patients receiving sitagliptin had a rapid improvement in PG may be useful when deciding the timing and optimal treatment regimen for patients with type 2 diabetes.

The results of the present study also suggest that glucagon suppression may cause hypoglycemia in the early stages of coadministration of sitagliptin and insulin or other insulin secretagogues. Therefore, careful attention must be paid to monitoring patients with low insulin secretory capacity.

In conclusion, sitagliptin may contribute to the rapid improvement of postprandial PG in Japanese patients with type 2 diabetes who are on a calorie-restricted diet. We suggest that any early reduction in blood glucose attributable to sitagliptin results mainly from suppression of excessive glucagon secretion. Major adverse reactions were limited to mild gastric symptoms.

\section{Study Limitations and Future Research}

This was a single-arm study without a control group on a calorie-restricted diet but without sitagliptin treatment. It was not possible to determine the relative contributions of diet and sitagliptin to the improvement in PG, increase in active GLP-1, and suppression of glucagon secretion. Therefore, it may not be appropriate to generalize the findings of the present study to Japanese patients with type 2 diabetes. Our next study will involve a greater number of patients and include a control group. Thus, we aim to confirm the results of the present study and to provide findings that are valid for the general population of Japanese patients with type 2 diabetes.
Acknowledgments The authors thank Mrs K. Fujikawa for her excellent assistance in blood sampling in MTT.

Conflicts of interest T. Katsuno, J. Miyagawa, M. Miuchi, and M. Namba received lecture fees from MSD. The other authors have no conflicts of interest to declare.

Open Access This article is distributed under the terms of the Creative Commons Attribution Noncommercial License which permits any noncommercial use, distribution, and reproduction in any medium, provided the original author(s) and the source are credited.

\section{References}

1. Japanese Ministry of Health, Labour and Welfare. National Health and Nutrition Survey, 2007 [in Japanese]. http://www. mhlw.go.jp/bunya/kenkou/eiyou09/dl/01-kekka.pdf. Accessed Aug 2014.

2. International Diabetes Federation. IDF diabetes atlas. 5th ed. Brussels: International Diabetes Federation; 2011.

3. Williams-Herman D, Engel SS, Round E, Johnson J, Golm GT, Guo H, et al. Safety and tolerability of sitagliptin in clinical studies: a pooled analysis of data from 10,246 patients with type 2 diabetes. BMC Endocr Disord. 2010;10:7.

4. Herman GA, Mistry GC, Yi B, Bergman AJ, Wang AQ, Zeng W, et al. Evaluation of pharmacokinetic parameters and dipeptidyl peptidase-4 inhibition following single doses of sitagliptin in healthy, young Japanese males. $\mathrm{Br} \mathrm{J}$ Clin Pharmacol. 2011;71:429-36.

5. Maeda H, Kubota A, Tanaka Y, Terauchi Y, Matsuba I, ASSETK Study Group. The safety, efficacy and predictors for HbA1c reduction of sitagliptin in the treatment of Japanese type 2 diabetes. Diabetes Res Clin Pract. 2012;95:e20-2.

6. Nonaka K, Kakikawa T, Sato A, Okuyama K, Fujimoto G, Kato $\mathrm{N}$, et al. Efficacy and safety of sitagliptin monotherapy in Japanese patients with type 2 diabetes. Diabetes Res Clin Pract. 2008;79:291-8.

7. Iwamoto Y, Taniguchi T, Nonaka K, Okamoto T, Okuyama K, Arjona Ferreira JC, et al. Dose-ranging efficacy of sitagliptin, a dipeptidyl peptidase-4 inhibitor, in Japanese patients with type 2 diabetes mellitus. Endocr J. 2010;57:383-94.

8. Katsuno T, Ikeda H, Ida K, Miyagawa J, Namba M. Add-on therapy with the DPP-4 inhibitor sitagliptin improves glycemic control in insulin-treated Japanese patients with type 2 diabetes mellitus. Endocr J. 2013;60:733-42.

9. Kim SA, Shim WH, Lee EH, Lee YM, Beom SH, Kim ES, et al. Predictive clinical parameters for the therapeutic efficacy of sitagliptin in Korean type 2 diabetes mellitus. Diabetes Metab J. 2011;35:159-65.

10. Muscelli E, Casolaro A, Gastaldelli A, Mari A, Seghieri G, Astiarraga B, et al. Mechanisms for the antihyperglycemic effect of sitagliptin in patients with type 2 diabetes. J Clin Endocrinol Metab. 2012;97:2818-26.

11. Katayama Y, Taniguchi T, Okuyama K, Fujimoto G, Ishii M, Ito $\mathrm{M}$, et al. Pharmacokinetics and pharmacodynamics of sitagliptin, a dipeptidyl peptidase-4 inhibitor, following repeated oral administration in healthy Japanese adult men [in Japanese]. J New Rem Clin. 2011;60:1139-59.

12. Holst JJ, Deacon CF, Vilsbøll T, Krarup T, Madsbad S. Glucagon-like peptide-1, glucose homeostasis and diabetes. Trends Mol Med. 2008;14:161-8.

13. Ohkura T, Fujioka Y, Sumi K, Nakanishi R, Shiochi H, Yamamoto N, et al. Sitagliptin improves the impaired acute insulin 
response during a meal tolerance test in Japanese patients with type 2 diabetes mellitus: a small-scale real-world study. Diabetes Ther. 2014;5:285-97.

14. Bosco D, Armanet M, Morel P, Niclauss N, Sgroi A, Muller YD, et al. Unique arrangement of $\alpha$ - and $\beta$-cells in human islets of Langerhans. Diabetes. 2010;59:1202-10.

15. de Heer J, Rasmussen C, Coy DH, Holst JJ. Glucagon-like peptide-1, but not glucose-dependent insulinotropic peptide, inhibits glucagon secretion via somatostatin (receptor subtype 2) in the perfused rat pancreas. Diabetologia. 2008;51:2263-70.

16. Tornehave D, Kristensen P, Rømer J, Knudsen LB, Heller RS. Expression of the GLP-1 receptor in mouse, rat, and human pancreas. J Histochem Cytochem. 2008;56:841-51.

17. Herman GA, Bergman A, Stevens C, Kotey P, Yi B, Zhao P, et al. Effect of single oral doses of sitagliptin, a dipeptidyl peptidase- 4 inhibitor, on incretin and plasma glucose levels after an oral glucose tolerance test in patients with type 2 diabetes. J Clin Endocrinol Metab. 2006;91:4612-9.

18. Aoki K, Masuda K, Miyazaki T, Togashi Y, Terauchi Y. Effects of miglitol, sitagliptin or their combination on plasma glucose, insulin and incretin levels in non-diabetic men. Endocr $\mathrm{J}$. 2010;57:667-72.

19. Nagai E, Katsuno T, Miyagawa J, Konishi K, Miuchi M, Ochi F, et al. Incretin responses to oral glucose load in Japanese nonobese healthy subjects. Diabetes Ther. 2011;2:20-8.

20. Miuchi M, Miyagawa J, Konishi K, Nagai E, Kitamura N, Yano $\mathrm{Y}$, et al. Morphometric analysis of pancreatic $\alpha$-cells in Japanese non-obese patients with type 2 diabetes mellitus [poster no. 1946-P]. Diabetes. 2011;60 Suppl. 1:A525. 